\title{
\&. $\bullet$
}

تأثير برنامج رياضي غذائي علي إنقاص الوزن لاي طالبات الفرقة الرابعة

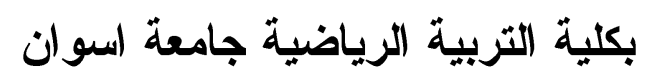

"د إسبرا عدلي رشاد

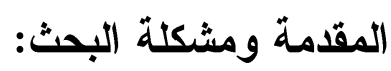

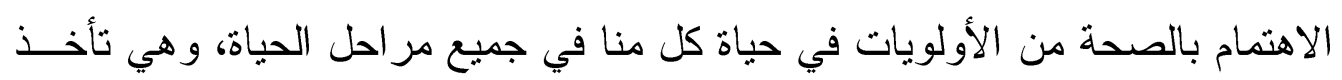

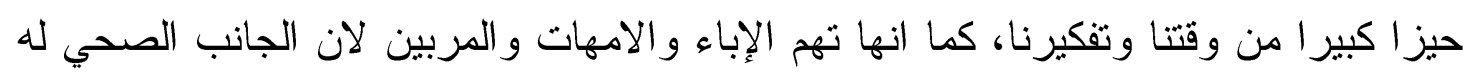
الأثر الأكبر في إمكانية الطلاب بأداء ادور اهم وواجباتهم تجاه الاخرين.

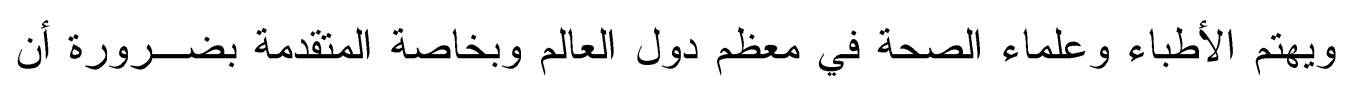

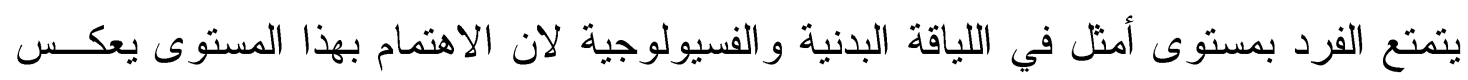

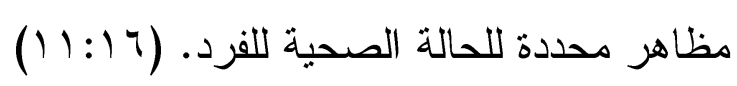

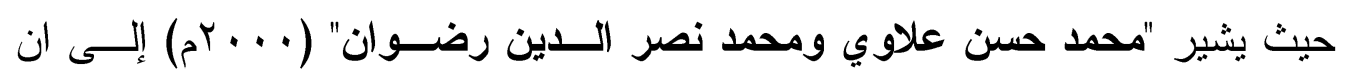

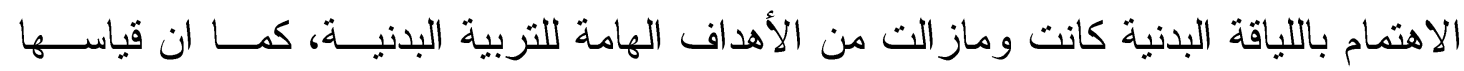

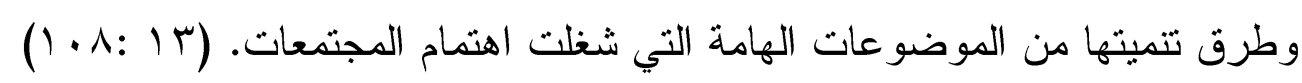

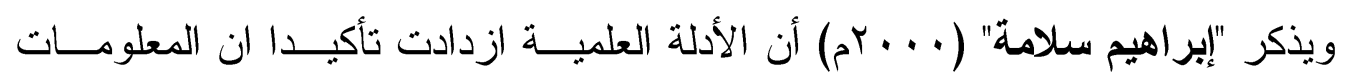

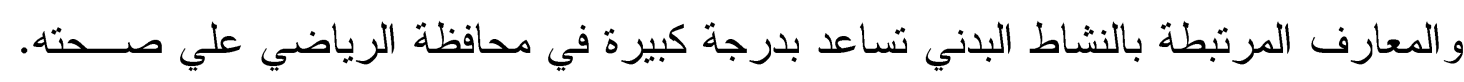
(r) :1)

أن الرياضة في العصر الذى نعيشه تمارس من اجل هدفين أساسيين وهما الرياضـــة

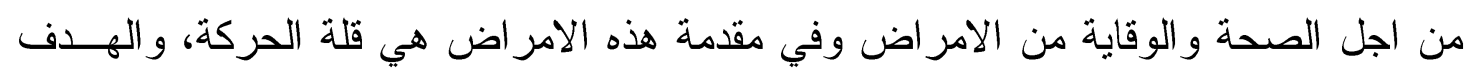

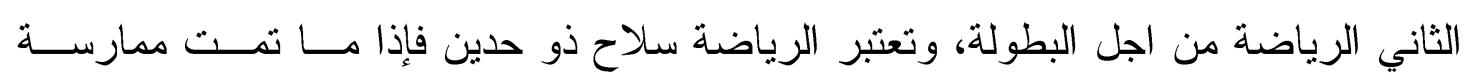
الرياضة مع إغفال الجانب الصحي تتتج اضرار صحية، لذلك يجب تقنين الممارسة الرياضية

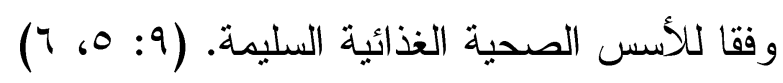

ومن أهم العلوم الحديثة التي شغلت العالم هو علم التخذية وهو علم حديث نسبيا علي التي يد علماء الكيمياء و الفسيولوجيا، وتعتبر التغذية فن و علم فعلى الرغم من أن الانسان تستجيب

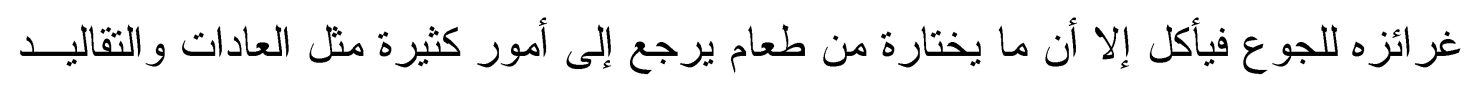
"مدرس بقسم التمرينات والجمباز و التعبير الحركي. مجلة أسيوط لعلوم وفنون التربية الرياضية 
الشعبية و الخبر ات المكتسبة، فتفضيل نوع معين من الأطعمة علــى نــوع اخــر لا يحــدده بالضرورة ما فيه من عناصر غذائية بل ما يميله عليه المجتمع وعاداته. (10 : ؟ب) ومما لاشك فيه أن من أهم واجبات علماء التخذية هو توجيه الفــرد و المجتمــع إلـى اختيار الأطعمة الجيدة وتكوين عادات غذائية سليمة وتغير العادات الغذائية الخاطئة وهذا مـــا يحتاج إلى در اسة تغير المعتقدات و العادات المسبقة حول أطعمة معية.

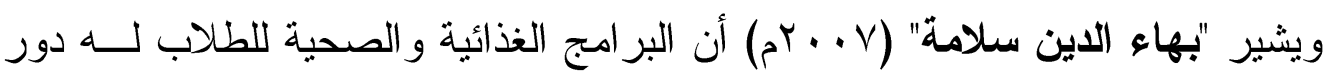
هام في التتمية وتحقيق الإنجاز ولكي يتم تحقيق ذلك في أي مجتمع يجب أن يعمل المسئولين داخل الكليات و المدارس علي تتمية الوعي الغذائي و الصحي للطلاب. (؟:A ( ) وتعتبر مكونات الجسم لها أهمبة كبيرة في تطوير مستوي الأداء حيث أنه من خــلال تحديد وتقدير نسبة مكوناته يمكن الحصول علي البيانات الحقيقية المعبرة عن الحالة الصحية، ولضمان الحفاظ علي وزن الجسم، لابد من التوازن بين مدخلات ومخرجات الطاقة لضــمان عدم حدوث أي خلل. وتعتبر زيادة نسبة الدهون عن النسبة الطبيعية من عوامل الخطر التي تـؤدى إلــي زيادة المشاكل الصحية للفرد، و انخفاض مستوي اللياقة البدنية، كما تعد السمنة مصدر أساسي للكثير من الامر اض، كما انها تسبب حملا زائدا علي مفاصل الجسم. ( سمب. . ( ) وتذكر "الهام إسماعيل شلبي" (ب . . rم) نقلا من محمد نصــر الــدين رضـــوان أن تركيب الجسم يعد من اهم المؤشرات التي تكثف عن الحالة الصحية و اللياقة البدنية للفــرد، ويتطلب فهم تركيب الجسم أن نأخذ في الاعتبار مكونين أساسيين هما : وزن الانسجة الدهنية،

$$
\text { ووزن الانسجة غير الدهنية. (0. : 11) }
$$

ويذكر "ابو العلا عبد الفتاح واحمد نصر الاين" (ب99 (م) الي ان نسبة الدهن تبلــنغ

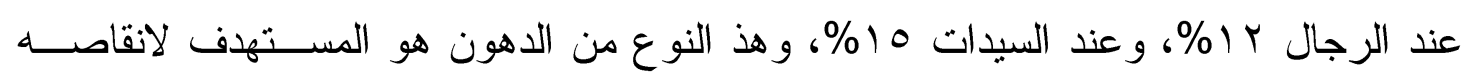
وتتظيم التغذية، وان الحد الأدنى للدهون المصاحبة للحالة الصحية الجيدة و الغذائية المناسبة في

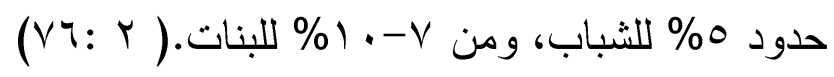
ومن أهم المؤشرات العامة للبدانة عندما يزيد مؤشر كتلة الجسم عن ·ـكجــم /مس،

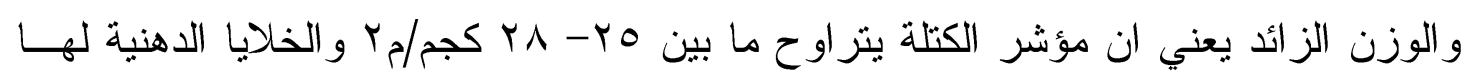


مرحلتين، احدهما في الطفولة المبكرة، والثانية في مرحلة المر اهقة، كذلك الجينات تحدد عدد

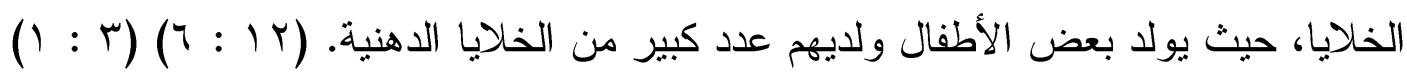
ويذكر "المعهد القومي للصحة" (9 . . r.م) الي ان معرفة مؤشر كتلة الجسم يعد احدي

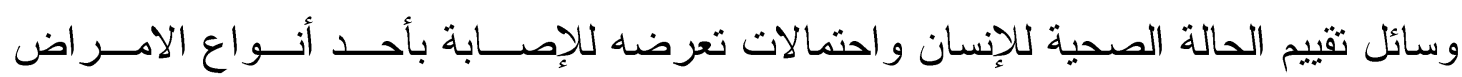
المزمنة. (^): (9^0)

وتعتبر السمنة من المشاكل الرئيسية التي توجد الان علي مستوي العالم، وهي مشكلة

الفرد الذي يستهلك كمية من الطاقة التي تفوق احتياجاته، ويحدث هذا الاختلال فـــي الطاقــة نتيجة عدة عو امل مثل نمط الغذاء الذي تتاوله الطلاب و الذي تتشأ نتيجة العــادات المتصــلة بالنشاط و الر احة و العلاقات الاسرية و الاجتماعية. (V) إلي ان الهدف الأساسي من التربية الصحية هو تغيير المفاهيم و العادات والاتجاهـات الي مفاهيم وعادات وسلوك تتماشي مع القواعد الصحية السليمة، ولتحقيق ذلــــ لابـــد مــن الاستعانة بأحدث الوسائل التربوية التي تساعد علي تدعيم الممارسة وتكوين العادات الصحية التي تحافظ علي الصحة وتساعد علي الوقاية من الامر اض. ومن خلال عمل الباحثة مدرس تمرينات بكلية التربية الرياضية لاحظت بزيادة فـي الوزن و البدانة لطالبات الفرقة الر ابعة وخاصة بعد عودتهم من توقف لمدة كبيرة نظر الجائحة كرونا واستخدام التكنولوجيا والتي توفر الكثير من الحركة، وانتشار مطاعم الوجبات السريعة و التي تحتوى علي نسبة كبيرة من الدهون، كل ذلك أدي إلي زيادة كتلة الجسم، وقلة مستوي اللياقة البدنية. و الأهم قناعة الباحثة بأن الاهتمام بالتربية الصحية و الغذائية هو هدف أساسـي مــن

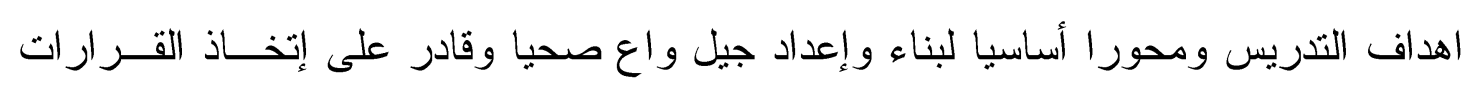

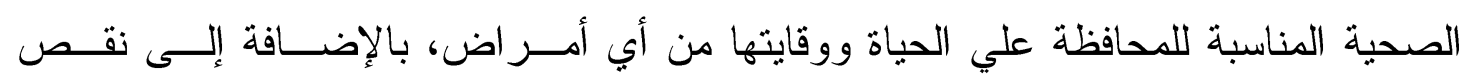
المعلومات والمعارف المتعلقة بالغذاء و التغذية تعتبر من أهم أسباب الكثير من مشكلات سوء التغذية. لذلك مما استدعي الباحثة التفكير في محاولة بناء برنامج رياضي غــذائي و التعــرف علي تأثيره علي إنقاص الوزن لطالبات الفرقة الر ابعة بكلية التربية الرياضبة جامعة أسوان. 


\section{$\varepsilon \cdot 1$}

أهداف البحث:

يهدف هذا البحث إلى التعرف علي تأثير برنامج رياضي غذائي علي إنقاص الــوزن لاي طالبات الفرقة الرابعة كلبة التربية الرياضية جامعة اسوان.

فروض البحث:

- - توجد فروق دالة إحصائية بين القياسات القبلية و البعدية للمجموعة التجريبية في مستوي الثقافة الصحية و الغذائية لصالح القياسات البعدية.

- توجد فروق دالة إحصائية بين القياسات القبلية والبعدية للمجموعة التجريبية في متغيرات مؤشر كتلة الجسم لصالح القياسات البعدية.

- توجد فروق دالة إحصائية بين القياسات القبلية والبعديــة للمجموعــة التجريبيــة فـي المتغير ات البدنية لصالح القباسات البعدية. مصطلحات البحث:

$$
\text { - البرنامج (البذني- الصحي الغذائي): }
$$

هو برنامج تدريبي مقنن يعطي الطالبات شروط وتعليمات صحية غذائية يلتزم بهــا

$$
\text { خلال مدة معينة ( تعريف إجرائي). }
$$

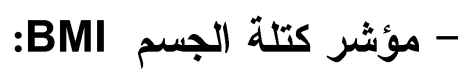

هو مؤشر يعكس تتاسب طول الجسم مع كتلته ( وزن الجسم ) ويمكن حسـابة مــن

$$
\text { خلال قسمة وزن الجسم بالكيلو جرام / مربع الطول بالمتر • ( } 11 \text { : 10) }
$$

- القياسات الجسمية :

قياس أجزاء الجسم البشري وله أهمبة كبيرة في تقويم نمو الفرد، وهو مؤشر يعبـر

عن حالة النمو عند الأفراد للتعرف علي الوزن و الطول والمحيطات والأعر اض. (ج (: جسم)

$$
\text { خطوات وإجراءات البحث : }
$$

منهج البحث :

استخدمت الباحثة المنهج التجريبي وذلك لملائمته للبحث، وذلك بأســتخدام التصــميم التجريبي ذات القياس البعدي لمجمو عتين إحدهما تجريبية والأخرى ضابطة.

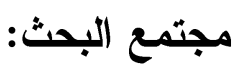




\section{$\varepsilon \cdot 9$}

يمثل مجتمع البحث طالبات الفرقة الرابعة كلية التربية الرياضية جامعة أسوان للعــام

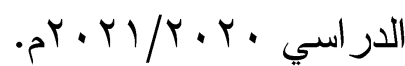

$$
\begin{aligned}
& \text { عينة البحث: }
\end{aligned}
$$

تم اختيار عينة البحث بالطريقة العمدية من طالبات الفرقــة الر ابعــة كلبــة التربيــة

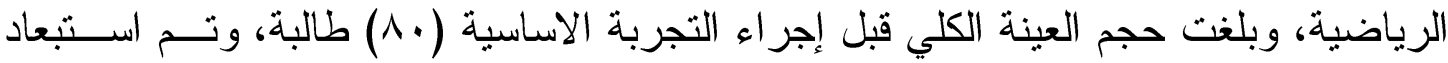
عدد ( • () طالبات لإجر اء التجربة الاستطلاعية عليهم، ليصبح قو ام عينة البحث (• V) طالبة، تم تقسيمهم الي مجموعتين احدهما تجريبية و عددها (مب) طالبة، و الاخري ضابطة وعـددها (0ب) طالبة، وقامت الباحثة بإجر اء التجانس بين متغير ات البحث (الطول، الـــوزن، الســن، المتغير ات البدنية و الفسيولوجية).

جدول (1)

توصيف عينة البحث

\begin{tabular}{|c|c|c|c|}
\hline العدد & \multicolumn{2}{|c|}{ نوع العبنـة } & م \\
\hline o r & ضابطة & \multirow{2}{*}{ اساسية } & \multirow[t]{2}{*}{1} \\
\hline ro & تجريبية & & \\
\hline 1. & \multicolumn{2}{|c|}{ استطلاعية } & r \\
\hline$\Lambda$. & \multicolumn{2}{|c|}{ المجمو ع } & r \\
\hline
\end{tabular}

وقام الباحث بحساب مدى إعتدالية المتغير ات الاساسية و البدنية كمــا هـــ موضــح

بالجدول رقم (r).

جدول (r) (r)

التوصيف الأحصائى لبيانات عينة البحث الكلية فى المتغيرات الأساسية وبعض المتغيرات البدنية ن= ، البن

\begin{tabular}{|c|c|c|c|c|c|c|}
\hline معامل & التنفاطلح & 1المهـيارى & الوسيط & المتوبسط & المتغيرات & \\
\hline.$r V Y$ & $\cdot . \wedge V T$ & سMV. & rI & $r . .9 \varepsilon$ & السن & $\bar{z}$ \\
\hline$\cdot, \leq \leqslant 0-$ & r & سז,ד & 17. & 109.7 & الطول & \\
\hline $.0 \leqslant 1$ &..$\{\leqslant 1-$ & $7 . \wedge$. & 79 & $79 . \wedge r$ & الوزن & \\
\hline
\end{tabular}


$\varepsilon 1$.

تابع جدول (r)

التوصيف الأحصائى لبيانات عينة البحث الكلية فى المتغيرات الأساسية وبعض المتغيرات

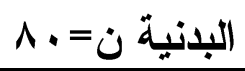

\begin{tabular}{|c|c|c|c|c|c|}
\hline معالتامل & التفالطح & المعيارى الانــراف & الوسيط & المسابو & المتغيرات \\
\hline..$\leqslant 70$ & r. $9 \mathrm{~V}$ & $1.9 \varepsilon$ & $r V . V Y$ & rV.ru & مؤشر كتلة الجسم \\
\hline. $.1 \wedge T_{-}$ & - & 1.19 & 1. & 1.10 & سمك ثنايا الجلد منطقة البطن \\
\hline $.0 Y 1$ & $\ldots r-$ & $1 . \lambda r$ & $r$. & $19.1 \mathrm{r}$ & النسبة المئوية للدهون \\
\hline$\ldots$.. V - & $1 . . v-$ & $1 . \leqslant 9$ & iv & IV..r & الرشاقة \\
\hline. . 79 & $1 . .1-$ & שזT. & r.or & r. $\leqslant V$ & المرونة \\
\hline
\end{tabular}

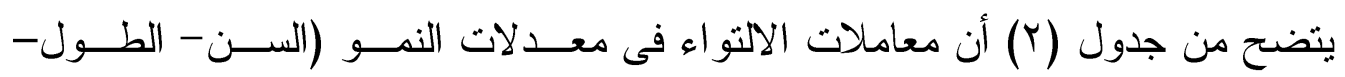

الوزن-مؤشر كتلة الجسم- سمك ثنايا الجلد- النسبة المئويــة للــدهون القــدرات البدنيــة)

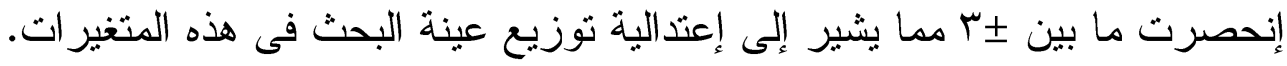

$$
\text { جدول (r) }
$$

\begin{tabular}{|c|c|c|c|c|c|c|}
\hline \multirow{2}{*}{ ق قيمة ت } & \multicolumn{2}{|c|}{ المجمو عة الفابـطة } & \multicolumn{2}{|c|}{ المجموعة التجريبية } & \multirow{2}{*}{ المتغيرات } & \\
\hline & $r_{\varepsilon}$ & $r_{\rho}$ & $\varepsilon$ & ما & & \\
\hline . THY & $\cdot$, VTr & $r, \cdot \cdot 1$ & $\cdot, Y Y I$ & $r \cdot, 90$ & السن - السن & \\
\hline $1,1 \pi$ & $7, \mathrm{~V} T$ & $17 ., \varepsilon$. & IV,rr & $107, \lambda r$ & 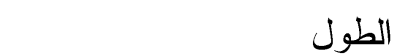 & \\
\hline . & 7,91 & $v \cdot, 10$ & $7, \wedge$ & 79,11 & الوزن & $\sqrt{3}$ \\
\hline., $00 \mathrm{r}$ & $r, r \cdot$ & $Y Y, O \leqslant$ & $1, \lambda$ & $Y V, Y V$ & مؤشر كتلة الجسم & \\
\hline $1, \wedge т$ & $\cdot, 9 r_{0}$ & $1 \cdot, \cdot r$ & $1, r \mu$ & $9, \vee \wedge$ & سمك ثنايا الجلد منطقة البطن & \\
\hline 1,ro & $1, \leqslant 0$ & $r \cdot, .0$ & $r, .1$ & $19, \leqslant 1$ & النسبة المئوية للدهون & \\
\hline., $7 r q$ & $1,0 \mathrm{~V}$ & $\mid V, \cdot A$ & $1, \leqslant 0$ & 17,10 & الرشاقة & $\overline{\mathrm{y}}$ \\
\hline., $70 \leqslant$ & . & $r, \varepsilon r$ & . שז, & r,Or & المرونة & \\
\hline
\end{tabular}

تكافؤ المجموعتين التجريبية والضابطة فى المتغيرات الأساسية وبعض المتغيرات البذنية

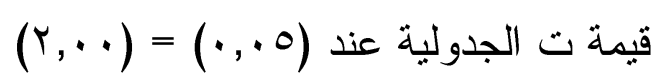


يتضح من الجدول (r) عدم وجود فروق دالة إحصائياً عند مســتوي (0...) بـين

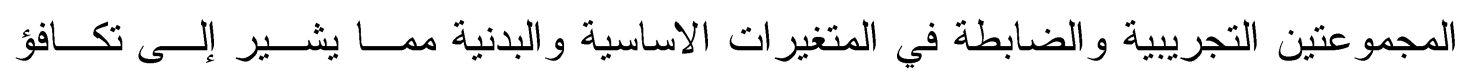
مجموعتى البحث في هذه المتغير ات. متغيرات البحث : مجنو :

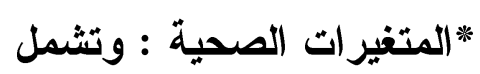
معدلات النمو (الوزن- الطول- العمر - مؤشر كتلة الجسم). القياسات الانثروبومترية (سمك ثنايا الجلد في منطقة البطن).

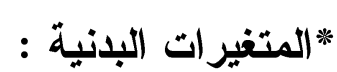
اختبار ات اللباقة البننية "الرشاقة : الجري المكوكي

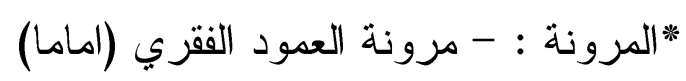
- مرونة العمود الفقري (خلفا)

الأدوات المستخدمة : * جهاز الرستاميتير لقياس الطول (بالسنتيمنز). * ميزان طبي لقياس الوزن بالكيلو جرام * حساب مؤشر كتلة الجسم عن طريق المعادلة :

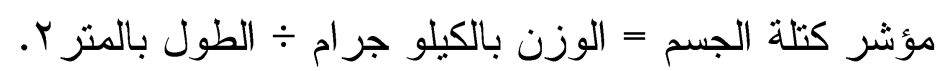
"جهاز Skin fold Caliper لقياس سمك ثنايا الجلد و الدهن.

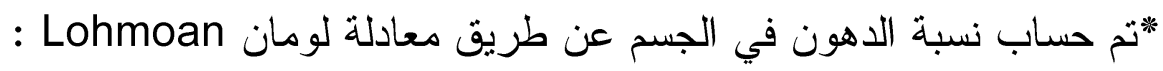

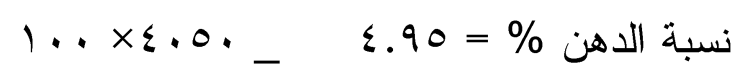
* تم حساب وزن الدهن كثافة الجسم

Fat Weight(FW) : عن طريق المعادلة الثالية وزن الدهن = وزن الجسم × نسبة الدهن في الجسم

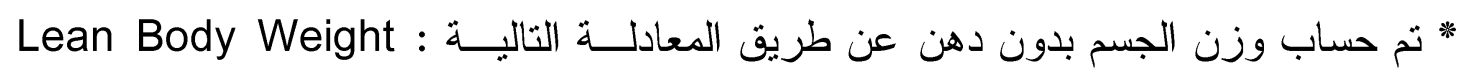
(LBW) 


$$
\begin{aligned}
& \text { وزن الدهن بدون دهن =وزن الجسم-وزن الدهن. (YV:IY) } \\
& \text { خطوات الاستبيان : }
\end{aligned}
$$

استعانت الباحثة في جمع البيانات بالمصادر الاتية :

- تحليل المر اجع العربية والأجنبية في مجال الصحة العامة والتغذية. - الاستعانة بمجموعة من الخبر اء المتخصصين العاملين في مجال التربية الصحية.

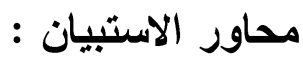

بعد القراءات النظرية وتحليل المراجع و الدراسات العربية والأجنبية قامـــت الباحثــة

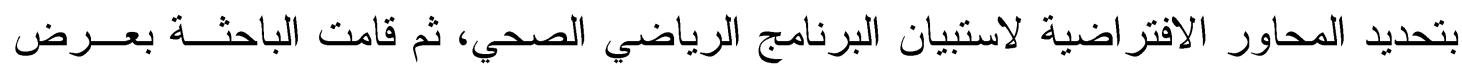

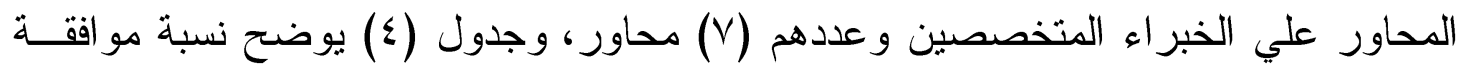

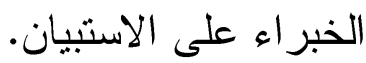

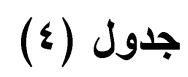

\begin{tabular}{|c|c|c|c|c|c|}
\hline \multicolumn{2}{|c|}{ عدم الموافقة } & \multicolumn{2}{|c|}{ الموافقة } & \multirow[t]{2}{*}{ المحاور الافتراضية } & \multirow[t]{2}{*}{ م } \\
\hline$\%$ & $\leq$ & $\%$ & ك & & \\
\hline- & _- & $\% 1 \ldots$ & v & الصحة الثخصية & 1 \\
\hline$\% 17.0$ & 1 & $\% \wedge r . ॰$ & 1 & نظام الحياة اليومية & r \\
\hline _ & _ & $\% 1 \ldots$ & v & التغذية السليمة & $r$ \\
\hline & - & $\% 1 \ldots$ & v & فترات النوم & $\varepsilon$ \\
\hline$\% 17.0$ & 1 & $\% \wedge$ \%.॰ & 7 & البيئة السليمة & 0 \\
\hline - & _- & $\% 1 \ldots$ & v & ممارسة الرياضة & 7 \\
\hline$\% 17.0$ & 1 & $\%$ \%४.० & 7 & القو ام الصحي السليح & v \\
\hline
\end{tabular}

نسبة مو افقة الخبر اء (ن V ( )

ويتضح من جدول (ع) انه تم قبول جميع المحاور من قبل الباحثة. الار اسة الاستطلاعية :

تم اجر اء الدراسة الاستطلاعية علي عينة عشو ائية من الطالبات قو امها (• (1 طالبات)

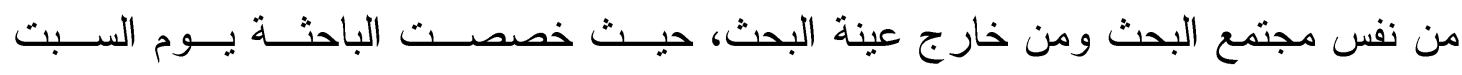

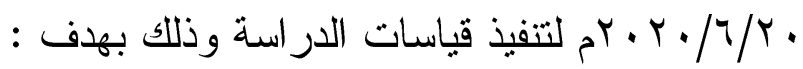


* التعرف علي الصعوبات التي من الممكن ان تحدث أثناء تنفيذ البحث. * التأكد من صلاحية سلامة المكان. * التأكد من مدي ملائمة التمرينات.

* التأكد من زمن الوحدة التدريبية مع الثدة للوصول الي اقصي معدل للنبض المطلوب. المعاملات العلمية لإختبار ات البحث:

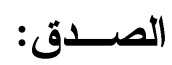

قامت الباحثة بإستخدام صدق التمايز، وذلك من خلال إجراء الإختبار ات علي عينــة مميزة و هم عينة البحث الإستطلاعية، و المجمو عة غير المميزة وهم من طالبات الفرقة الرابعة بكلية التربية الرياضية جامعة أسوان، وقد قامت الباحثة بحساب دلالة الفروق بين المجمو عتين المميزة و غير المميزة للتأكد من صدق الإختبار ات، و الجدول رقم (0) يوضح ذلك.

(•)

\begin{tabular}{|c|c|c|c|c|c|}
\hline \multirow{2}{*}{ قيهة } & \multicolumn{2}{|c|}{ المجمو عة غير المميزة } & \multicolumn{2}{|c|}{ المجمو عة المميزة } & \multirow{2}{*}{ المتغيرات البدنية } \\
\hline & $r_{\varepsilon}$ & $r^{5}$ & le & م5 & \\
\hline$r, \leqslant \wedge$ & Y,Y & $r \cdot, r$. & $1, r \leq$ & $\mid v, \varepsilon$. & الرشاقة \\
\hline$r, O r$ & $\cdot, 7 \leq 7$ & $1, \vee \wedge$ & $\cdot, 0 \vee \wedge$ & $Y, \Sigma V$ & المرونة \\
\hline
\end{tabular}

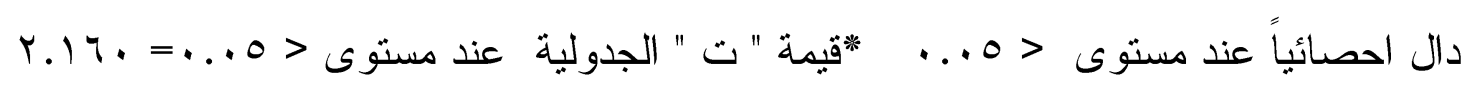
يتضح من جدول (0) وجود فروق دالة إحصائيا بين كلا مــن قياســات المجموعــة

المميزة و الغير مميزة لصالح أفر اد المجموعة المميزة حيث أن قيمة (ت) المحسوبة قد فاقــت قيمتها الجدولية عند مستوى 0 . , ، و هذا يعني قدرة الإختبار ات على التمبيز بين المسـتويات وبذلك تكون صادقة لقياس الصفات التي وضعت من أجلها. الثبـات:

استخدم الباحث طريقة تطبيق الإختبار و إعادة تطبيقه (Test - Re test)، لحسـاب

ثبات المقياس، وذلك عن طريق حساب معامل الإزتباط بين التطبيقين على نفس المجموعـة الاستطلاعية. و الجدول (T) يوضح ذلك.

مجلة أسيوط لعلوم وفنوز التربية الرياضية 
جدول (ا) (الاول

\begin{tabular}{|c|c|c|c|c|c|}
\hline \multirow{2}{*}{ قيمة ر } & \multicolumn{2}{|c|}{ التطبيقو الثانى } & \multicolumn{2}{|c|}{ التطبيزو 1لاول } & \multirow{2}{*}{ المتغهيرات البدنية } \\
\hline & $r_{\varepsilon}$ & $r_{\rho}$ & ع & مر & \\
\hline$\cdot, 9 \leq 1$ & 1,07 & iv & $1, r \leq$ & IV, $\varepsilon$. & الرشاقة \\
\hline$\cdot, 9 \vee \leqslant$ &., $00 \leqslant$ & $r, \leqslant 0$ & $\cdot, 0 \vee \wedge$ & $r, \Sigma V$ & المرونة \\
\hline
\end{tabular}

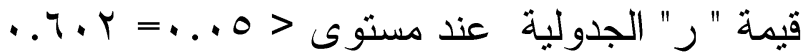

يتضح من جدول رقم (آ) وجود علاقة ارتباطية موجبة قوية بين كل مسـن درجـات

العينة الاستطلاعية فى التطبيق الأول ودرجات التطبيق الثانى لنفس المجموعة فى الاختبار ات البدنية، حيث جاءت قيم "ر" دالة احصائيا عند مستوى دلالة (0 . .))، و هــذا يعنـى ثبــات درجات الاختبار عند إعادة تطبيقه تحت نفس الظروف.

البرنامج الرياضي المقترح : الهُف من البرنامج : * تحسين حيوية أجهزة الجسم الداخلية بالجسم. * تحسين مؤشر كتلة الجسم بعد تطبيق البرنامج. * خفض نسبة تركيز الدهون بالدم.

* اكتساب الطالبات الوعي الرياضي و الغذائي من خلال تتمية الأفكار الخاصة بالصحة * اكتساب المعارف و المعلومات التي تمكن الطالبات من مواجهة اتجاهــاتهم السـلبية عـن الصحة و الغذاء و الرياضة لتمكنهم من مو اجهة سوق العمل.

\section{أسس وضع البرنامج :} * عدد مرات التدريب ثلاث مرات أسبو عيا. * الطالبة المشتركة في البرنامج يجب أن تقوم بالمشي نصف ساعة يومبا ماعدا أيام التدريب * يجب ان تكون شدة و حجم التدريب مناسبة لتحقيق أعلى معدل ممكن من بذل الطاقة. * يجب ان يتدرج مستوى إستهلاك الطاقة من المستويات المنخفضة إلى المستويات الأعلى. * تكنسب الطالبات الوعي الصحي الرياضي السليم. 


$$
\text { * أن يكون البرنامج في ضو أن الأهداف الموضوعة. }
$$

* أن يساعد البرنامج على اكتساب المعلومات و المعارف.

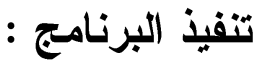

تدريب الطالبات علي تتفيذ مجموعة من التمرينات الهو ائية الخاصة لانقاص الــوزن

$$
\text { خلال (• ؟) دقيقة داخل صالة الألعاب بالكلية. }
$$

\begin{tabular}{|c|c|c|c|c|c|}
\hline شُدة الحمل & زاتندر الوحيبةات & عدد الوهدات & إجمالي الوحدات & عدد الاسابير & 1 \\
\hline اقصى معدل للنبض من & دقيقة & وحدات & وحدة تدربيية & أربع اسابيع & المرحلة الاولي \\
\hline اقصى معدل ل للنبض من & 0ـ دقيقة & س وحدات & وحدة تدريبية & أربع أسابيع & المرحلة الثانية \\
\hline معدل اقصي للنبض & .7 دقيقة & "r وحدات & وحدة تدريبية & أربع اسابيع & المرحلة الثالثة \\
\hline
\end{tabular}

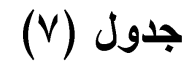

محتوي البرنامج المقترح

\begin{tabular}{|c|c|c|c|c|}
\hline (النتهدئة) & التمربنـات & الجز ء الرئيسـى & 11اءanماء & أجزاء الوحدة \\
\hline مق & اق & ه اق & مق & لوحدة الاولي \\
\hline 0ق & اق . & • זق & اق . & الوحدة الثانية \\
\hline مق & • & هـق & (ق & الوحدة الثالثة \\
\hline
\end{tabular}

التوزيع الزمني لكل وحدة :

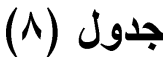

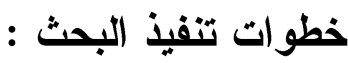

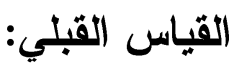

قامت الباحثة بإجر اء القياس القبلي علي المجموعة التجريبية و الضابطة في الفترة من

$$
\begin{aligned}
& \text { تفو } \\
& \text { تنفيذ تجربة البحث : }
\end{aligned}
$$




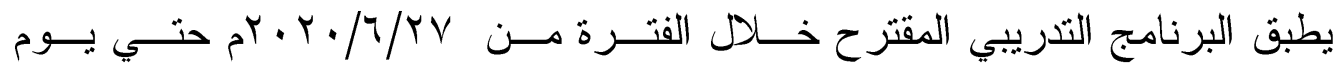

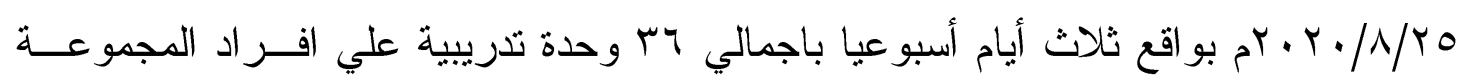
التجريبية.

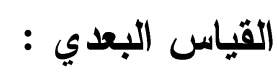

قامت الباحثة بإجر اء القياس البعدى علي افراد العينة قيد البحــث فــي الفتـرة مــن

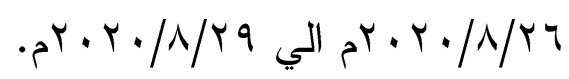

المعالجات الإحصائية المستخدمة : - المعالجات الإحصائية. - المتوسط الحسابى.

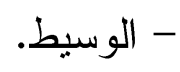
- الانحر اف المعياري. - معامل التفلطح. - معامل الالتو اء. - اختبار (ت) للمجمو عة الواحدة. - النسبة المئوية. - معامل ارتباط بيرسون. - نسبة التحسن. عرض ومناقشة النتائجج: أولاً: عرض ومناقشة نتائج الفرض الأول والأى ينص على: "توجد فروق دالة احصائياً بين القياسين القبلى والبعدى للمجموعة التجريبية بالنسبة لإنقاص الوزن وبعض المتغيرات البدنية لدى عينة البحث ولصالح القياس البعدى". 
جلول (^)

دلالة الفروق ونسبة التحسن بين متوسطات القياس القبلى و البعدى للمجموعة التجريبية

بالنسبة لأققاص الوزن وبعض المتغير ات البذنية ن=هـ

\begin{tabular}{|c|c|c|c|c|c|c|c|}
\hline \multirow{2}{*}{ نتسببة } & \multirow{2}{*}{ قيهمة } & \multicolumn{2}{|c|}{ القياسر البعدى } & \multicolumn{2}{|c|}{ القباسر القبلى } & \multirow{2}{*}{ المتتغيرات } & \\
\hline & & $r_{\varepsilon}$ & $r^{5}$ & le & ما & & \\
\hline$\% 1 \cdot, 1 r$ & $1 \varepsilon, \wedge V$ & $0, r q$ & $T Y, 70$ & $7, \wedge \wedge$ & $79, \times 1$ & الوزن & \\
\hline$\%) \cdot, \leqslant \leqslant$ & IY,r & 7,19 & ro,rq & 7,79 & rA, ro & مؤشر كتلة الجسم & $\overline{3}$ \\
\hline$\% \backslash r, \cdot T$ & $1 r, \varepsilon r$ & r & $\wedge, \uparrow$ & س & $9, \vee \wedge$ & سمك ثنايا الجلد & fo: \\
\hline$\% \wedge, . \circ$ & $i r, \cdot \Lambda$ & $1, \vee \wedge$ & $|v, 9|$ & $r, \cdot 1$ & $19, \leqslant 1$ & نسبة الدهون & \\
\hline$\% 19,17$ & $1 \Lambda, \cdot r$ & 1,17 & rT, & $1, \leqslant 0$ & 17,10 & الرشاقة & 亏. \\
\hline$\% \leqslant V, Y r$ & $\mid \Lambda, \vee \wedge$ & . & $r, v)$ & שדו, & r,or & المرونة & \\
\hline
\end{tabular}

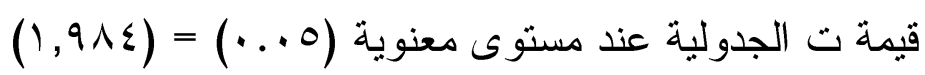

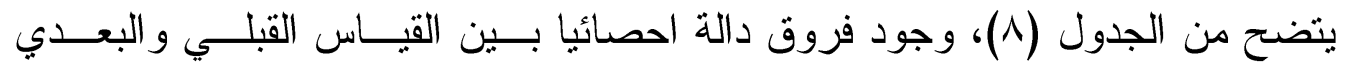

لمجموعة البحث التجريبية في متغير ات الوزن وبعض المتغيرات البدنية لدى عينــة البحــث

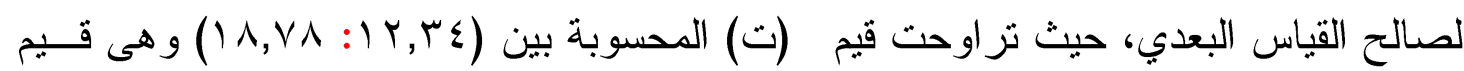
اعلى من القيمة الجدولية لاختبار (ت) عند مستوى الدلالة (0. . )، مما يؤكد تحسن مجموعة البحث التجريبية في هذة المتغيرات، كما يوضح الجدول معدل التحسن في تلك المتغير ات بين القياس القبلي و البعدي.

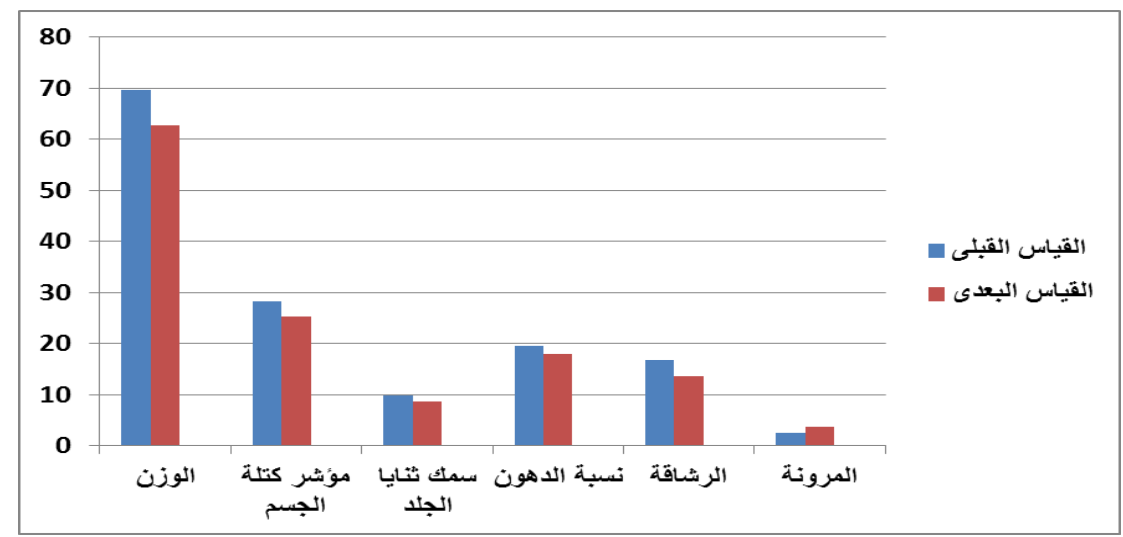

شكل (1) 
ثانيا: عرض ومناقشة نتائج الفرض الثانى والذى ينص على: "توجد فروق دالة احصائياً بين

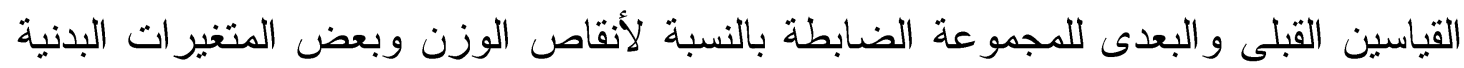
لدى عينة البحث ولصالح القياس البعدى.

جلول (9)

دلالة الفروق ونسبة التحسن بين متوسطات القياس القبلى والبعدى للمجموعة الضابطة

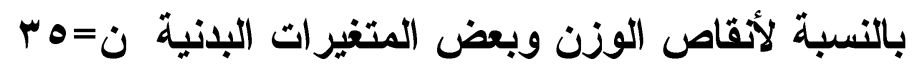

\begin{tabular}{|c|c|c|c|c|c|c|c|}
\hline \multirow{2}{*}{ 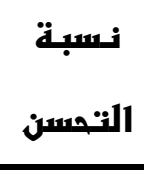 } & \multirow{2}{*}{ قبمة } & \multicolumn{2}{|c|}{ القباسر البعدى } & \multicolumn{2}{|c|}{ القباسر القبلى } & \multirow{2}{*}{ المتتغيرات } & \\
\hline & & $r_{\varepsilon}$ & $r^{5}$ & $\varepsilon$ & مر & & \\
\hline$\% 7,07$ & 10,91 & $7, \leqslant 0$ & TY, Y. & 7,91 & $V \cdot, \lambda 0$ & الوزن & \multirow{4}{*}{$\begin{array}{l}\overline{\bar{\lambda}} \\
\overline{3} \\
\overline{3}\end{array}$} \\
\hline \% & $17,0 \mathrm{~V}$ & $r, 10$ & ro,V $v$ & $r, r$. & $r V, O \varepsilon$ & مؤشر كتلة الجسم & \\
\hline$\% \vee, \wedge \wedge$ & 11,10 & • & $9, \vee \cdot$ &., $9 Y 0$ & $1 \cdot, 04$ & سمك ثنايا الجلد & \\
\hline$\%\{, 9 \wedge$ & $1 \leqslant, V$. & I,rv & $19, .0$ & $1, \leqslant 0$ & $r \cdot, \cdot 0$ & نسبة الدهون & \\
\hline$\% \backslash \cdot, \wedge \wedge$ & $M, \cdot \varepsilon$ & 1,11 & $10, r r$ & $1,0 \mathrm{~V}$ & $\mid v, \cdot A$ & الرشاقة & $\overline{\bar{y}}$ \\
\hline \%หт, Ł & $V, r_{1}$ & $1, .0$ & $r, \cdot r$ & . $7 \leqslant$. & $r, \varepsilon r$ & المرونة & \\
\hline
\end{tabular}

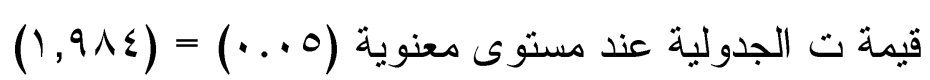

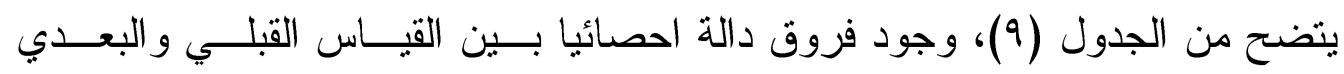

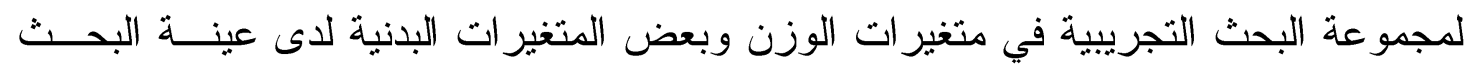

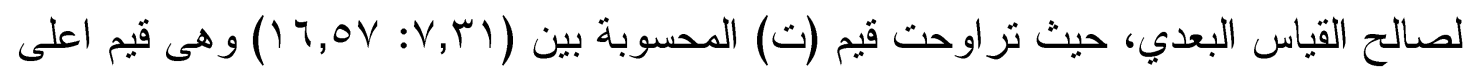
من القيمة الجدولية لاختبار(ت) عند مستوى الدلالة (0. . ·)، مما يؤكد تحسن مجموعة البحث الضابطة في هذة المتغيرات، كما يوضح الجدول معدل التحسن في تلك المتغير ات بين القياس القبلي و البعدي. 


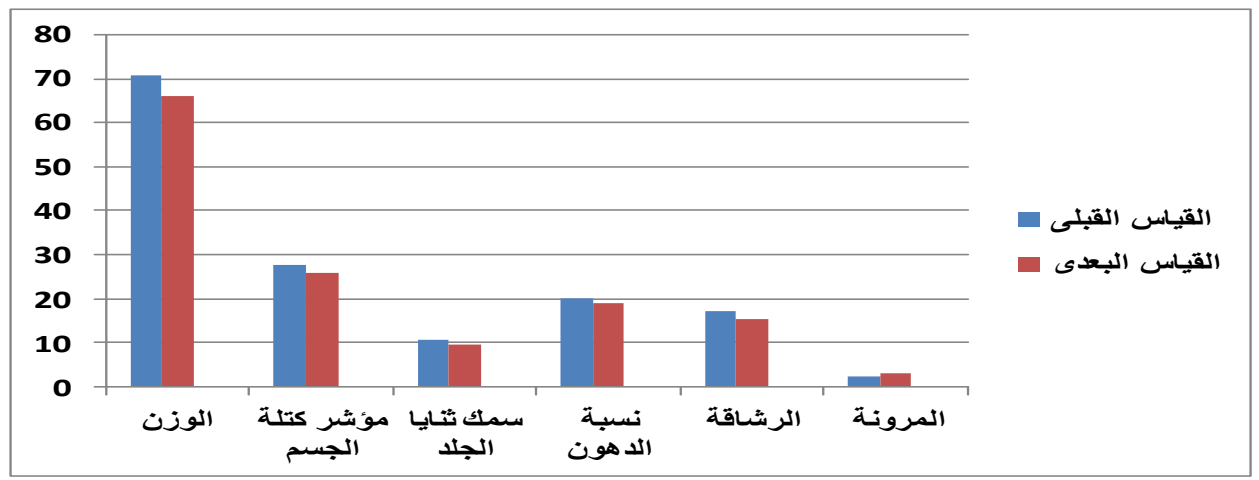

شكل (r)

عرض ومناقثة نتائج الفرض الثالث والذى ينص على: " توجد فروق دالة احصائياً بين

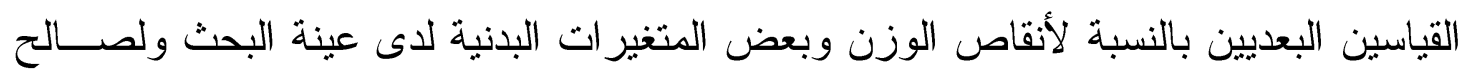
المجمو عة التجريبية.

\section{جلول (1. )}

دلالة الفروق بين متوسطات القياسيين البعديين للمجموعة التجريبية و الضابطة بالنسبة

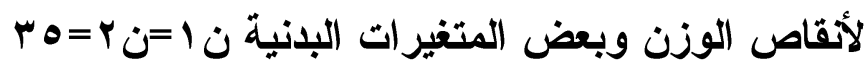

\begin{tabular}{|c|c|c|c|c|c|c|}
\hline \multirow{2}{*}{ قيمة ت } & \multicolumn{2}{|c|}{ المجمو عة الضابـطة } & \multicolumn{2}{|c|}{ المجمو عة التجريبية } & \multirow{2}{*}{ المتغيرات } & \\
\hline & $r_{\varepsilon}$ & $r^{5}$ & ع & 56 & & \\
\hline$r, \leqslant q$ & $7, \leqslant 0$ & $r T, r$. & 0,49 & $7 r, 70$ & 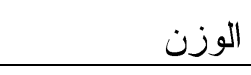 & \\
\hline$r, \wedge 1$ & $r, 10$ & Yo,V $v$ & $1, \wedge$. & $r \leq, \varepsilon$. & مؤشر كتلة الجسم & $\overline{3}$ \\
\hline$\varepsilon, 99$ &.,$q \mu \mathrm{V}$ & $9, v \cdot$ & $\cdot, 914$ & 7,7 & سمك ثنايا الجلد & : \\
\hline$r, 9 q$ & $1, r v$ & $19, .0$ & $1, \vee \wedge$ & $|v, q|$ & نسبة الدهون & \\
\hline$\varepsilon$, ऍ & $1, \lambda 1$ & $10, Y Y$ & 1,17 & rז, זו & الرشاقة & $\overline{\mathrm{z}}$ \\
\hline$r, \cdot v$ & $1, .0$ & $r, \cdot r$ & •, TTV & $r, v)$ & المرونة & \\
\hline
\end{tabular}

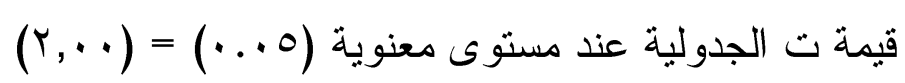

يتضح من الجدول (• ()، وجود فروق دالة احصائيا بين القياسين البعديين للمجموعة

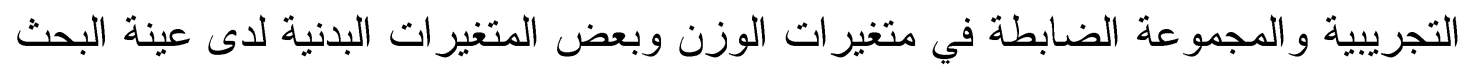




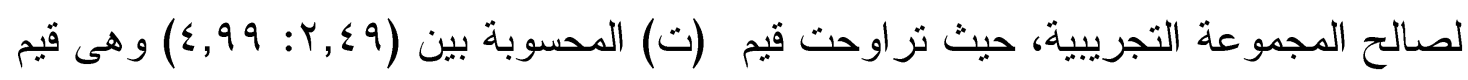

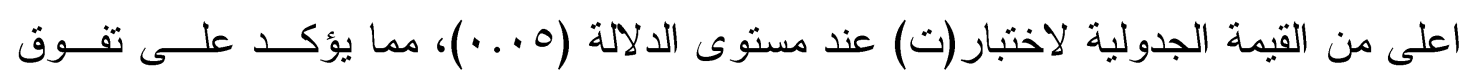
المجموعة التجريبية على المجموعة الضابطة في هذة المتغيرات.

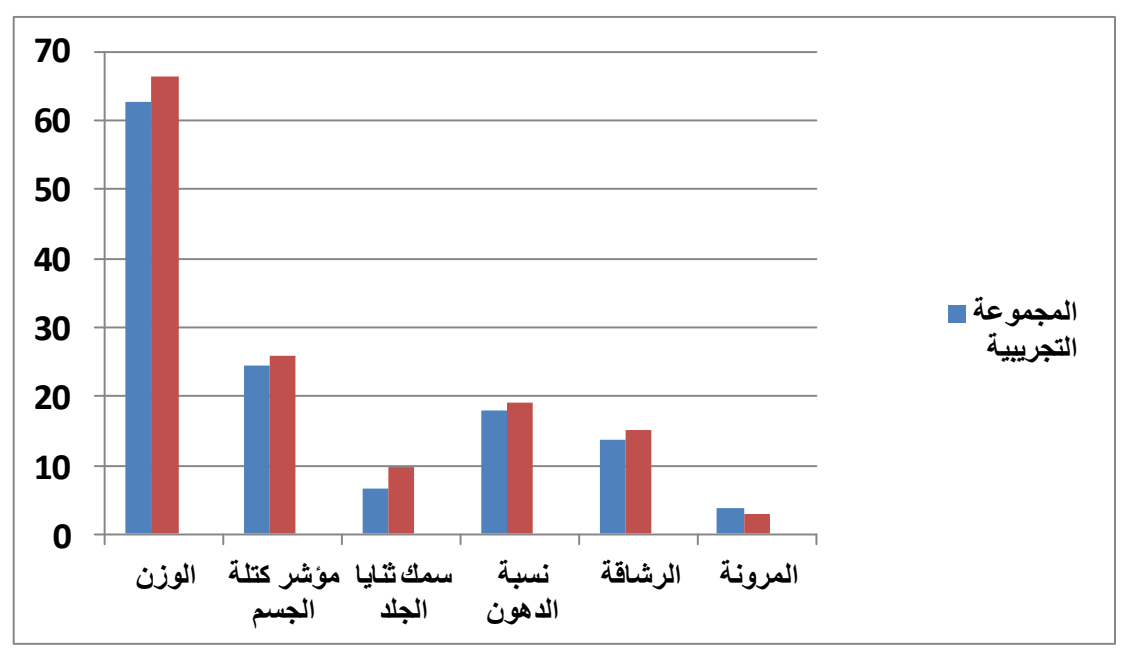

شكل (r) (r) (1) (1)

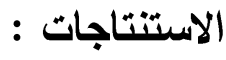

1- وجود فروق دالة احصائيا بين القياس القبلي والبعدى للمجموعة التجريبية لصالح القباس البعدي في جميع المتغير ات البدنية. r- وجود فروق غير دالة احصائيا بين القياسين القبلي والبعدي للمجموعة الضـــابطة فــي جميع المتغيرات البدنية. r- وجود فروق دالة احصائيا بين القياسين البعديين للمجموعتين الضابطة والتجريبية لصالح المجموعة التجريبية في المتغير ات البدنية. ع- وجود فروق غير دالة احصائيا بين القياسين القبلي والبعدي للمجموعة الضـــابطة فــي جميع المتغير ات (متغير سمك ثنايا الجلد في منطقة البطن). ه- وجود فروق دالة احصائيا بين القياس القبلي و البعدى للمجموعة التجريبية لصالح القياس البعدى (متغير سمك ثنايا الجلد في منطقة البطن). 


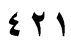

צ- وجود فروق بين متوسطى القياسين البعديين لدي المجموعة الضابطة والتجريبية نحــو

استجاباتهم في محاور الاستمارة من حيث (الصحة الشخصبة، نظـــام الحيــاة اليوميــة،

التغذية السليمة فترات النوم، البيئة السليمة، ممارسة الرياضة، القوام الصــحي الســليم

$$
\begin{aligned}
& \text { البرنامج الرياضي الصحي المقترح). } \\
& \text { التوصيات : }
\end{aligned}
$$

في ضوء النتائج التي توصلت لها الباحثة لذا توصى الباحثة بما يلى : 1- إدر اج مقرر الثقافة الصحية الرياضية ضمن المقررات الدر اسية. r- تطبيق برنامج اللياقة البدنية وتعميمه لما له الأثر الإيجابي في اكتساب الطالبات الثقافــة

$$
\text { الصحية الرياضية في ظل جائحة كورونا. }
$$

r- التخطيط الجيد للبر امج الصحية طبقا للأسس العلمية الحديثة.

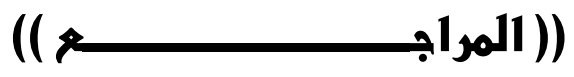

\section{أوبا: المراجه العربـة}

ا - إبراهيم احمد سلامة ( . . . rم): المدخل التطبيقي للقياس في اللياقــة البدنيــة، منشـــأة

$$
\text { المعارف، الإسكندرية. }
$$

ץ- أبو العلا عبد الفتاح واحمد نصر الدين (ب99 ام): فسيولوجيا ومورفولوجيا الرياضـي وطرق القياس و التقويم، دار الفكر العربي، القاهرة.

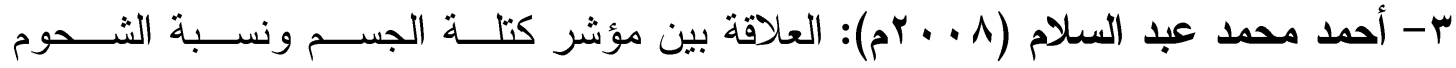
و الاصـابات لدي التلاميذ من r ا-10 سنة، مجلة البحوث الشاملة، مجلــد

$$
\text { با، العدد Y، جامعة الزقازيق. }
$$

ع - أنور عبدالله نوري (7 1 • r م): برنامج تربية صحية إلكتروني مقترح و اثره علي مستوي السلوك الصحي لدي طلاب المرحلة المتوسطة بدولة الكويت.

هـ إلهام إسماعيل محمد شلبي (r + . r م): اسـاسيات عامة في الصــحة العامــة و التربيــة الصحية، مذكرة منشورة، كلية التربية الرياضية للبنات، جامعسـة حلـــوان، 


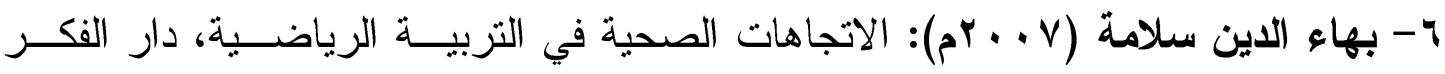

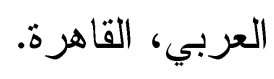

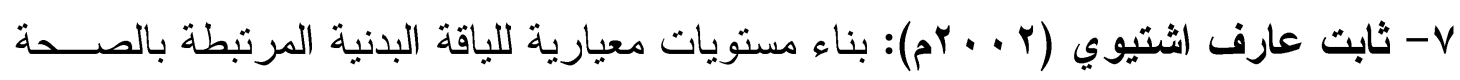

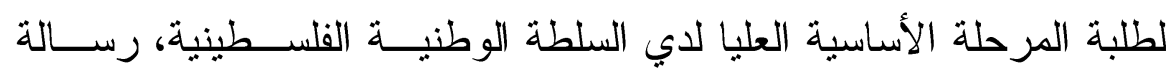
ماجستير، غير منشورة، كلية التربية الرياضية، الجامعة الأردنية، الأردن.

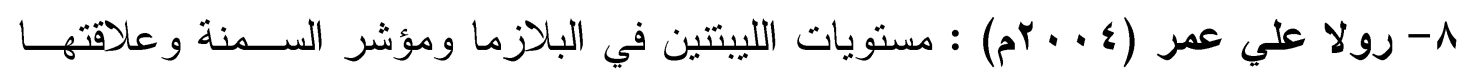
بالنمط الغذائي و العادات الغذائية في مجموعة من الســيدات الاردنيـات، رسالة ماجستير، الجامعة الأردنية، عمان، الأردن.

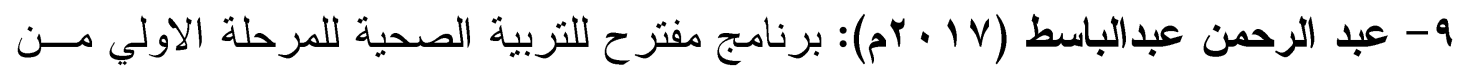

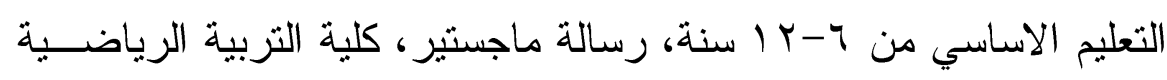
لاللنين بالقاهرة.

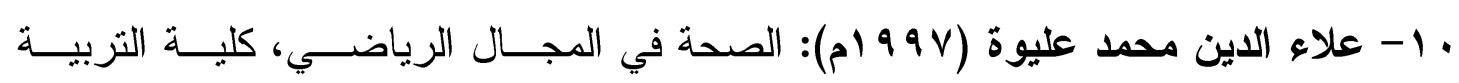
الرياضية للبنين، جامعة الإسكندرية.

1 - 1 فواز حميد خضير عباس (9 ( • rم): تأثير برنامج لياقة بدنية وتثقيف غذائي الكتروني

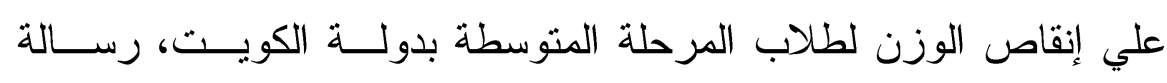
ماجستير ، كلية النزبية الرياضية، جامعة أسوان.

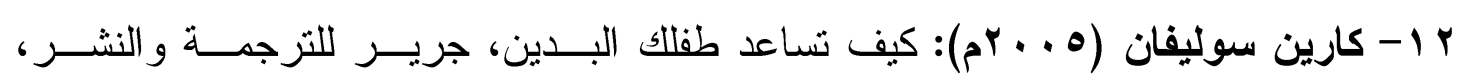
الرياض.

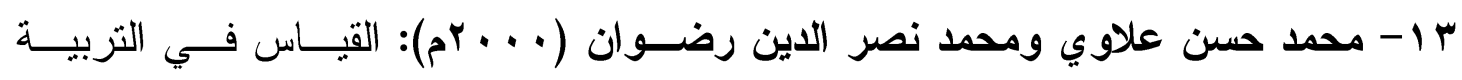
الرياضية وعلم النفس الرياضي، دار الفكر العربي، القاهرة.

ع ا - محمد سعد زغلول، مكارم حلمي أبو هرجة، هاني سعيد (1 . . rم) : تكنولوجيا التعليم و اساليبها في التربية الرياضية، مركز الكتاب للنشر ، القاهرة. ه - محمد نصر الدين رضوان (99V (9)) : المرجع في القياسات الجسمية، الطبعة الاولي، دار الفكر العربي، القاهرة. 


\section{$\varepsilon r \mu$}

7 ا - ناصر مصطفي محمد، مصطفي حسين باهي (r . . r م): بناء مقياس معرفـي للتقافــة

الصحية للرياضيين، المجلة الصحية لعلوم التربية الرياضية، جامعة طنطا،

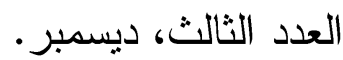

IV - هدى عبد الرحمن عبد السلام (9 (9 ام): اتجاهات السمنة بين طالبات الجامعة، رسالة ماجستير، كلية الاقتصاد المنزلي، جامعة حلوان، القاهرة.

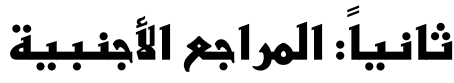

19- Chan, Ew \& Av, Ey \& Chan, BH, et al. (2003): Relation among physical activity, physical fitness, and self -perceived fitness in Hong Kong adolescents, the Hong Kong polytechnic university ,National Library Of medicine ,96(3pt):787-97-Jun.

20-Symontte, Pattied (1995) : The relationships of dietary patterns and exercise habits to risk factors for cardiovascular disease in Bahamian adolescent females, Howard, university. 